\title{
Short- and long-term results of laparoscopic adrenalectomy for Conn's syndrome
}

\author{
Mateusz Wierdak ${ }^{1}$, Grzegorz Sokołowski ${ }^{2}$, Michał Natkaniec $^{1}$, Karolina Morawiec-Sławek ${ }^{2}$, Piotr Małczak $^{1}$, \\ Piotr Major ${ }^{1}$, Alicja Hubalewska-Dydejczyk², Andrzej Budzyński ${ }^{1}$, Michał Pędziwiatr $^{1}$ \\ ${ }^{1} 2^{\text {nd }}$ Department of General Surgery, Jagiellonian University Medical College, Krakow, Poland \\ ${ }^{2}$ Department of Endocrinology, Jagiellonian University Medical College, Krakow, Poland
}

Videosurgery Miniinv 2018; 13 (3): 292-298

DOI: https://doi.org/10.5114/wiitm.2018.74833

\begin{abstract}
Introduction: The primary treatment of Conn's syndrome (CS) is laparoscopic adrenalectomy and aims to normalize arterial blood pressure and biochemical parameters.

Aim: To analyse short- and long-term results of laparoscopic adrenalectomy for Conn's syndrome (CS).

Material and methods: The analysis included 44 consecutive patients, who underwent laparoscopic adrenalectomy between 2004 and 2015 for CS. We analysed short-and long-terms results of operations. All patients were followed up 6 and 24 months after surgery to determine changes in the biochemical parameters, and clinical regression of arterial hypertension. We also evaluated the aldosteronoma resolution score (ARS) in predicting the resolution of hypertension.

Results: No conversions were needed. Complications occurred in 5 (11.4\%) patients. Preoperative hypokalaemia and hypernatraemia were present in $83.4 \%$ and $15.8 \%$ of patients, respectively. After surgery, both hypokalaemia and hypernatraemia resolved in all patients. At the follow-up 6 months after the surgery, only 11.3\% of patients had complete remission (CR) of hypertension. In 43.2\% of cases we observed partial remission (PR). After 24 months CR was found in $13.6 \%$ of patients, $45.5 \%$ patients fulfilled criteria for $P R$, and $29.5 \%$ of patients changed the group of remission comparison to the first follow-up visit. Only $50 \%$ of patients with an ARS of 4 or 5 points achieved CR 6 months after surgery.

Conclusions: Laparoscopic adrenalectomy is a safe method of treatment for CS. Although it effectively eliminates electrolyte imbalance, it does not allow for the CR of hypertension in the majority of patients, especially in the elderly group. We did not find ARS to be an effective tool in predicting postoperative resolution of hypertension.
\end{abstract}

Key words: laparoscopic adrenalectomy, adenoma, adrenal tumour, long-term outcomes, Conn's syndrome, aldosteronoma.

\section{Introduction}

Conn's syndrome (CS), the primary hyperaldosteronism caused by adrenal adenoma, is one of the most common causes of secondary hypertension [1]. Nowadays, the primary surgical treatment of CS is laparoscopic or retroperitoneoscopic adrenalectomy.
It is performed by a standard multiport or single incision approach and aims to normalize arterial blood pressure and biochemical parameters. It is considered a safe procedure with low mortality and significantly lower incidence of postoperative complications in comparison to the open approach [2-4]. While there are numerous studies analysing short-term outcomes,

\section{Address for correspondence}

Michał Pędziwiatr MD, PhD, 2 nd Department of General Surgery, Jagiellonian University Medical College, 21 Kopernika St, 31-501 Krakow,

Poland, phone: +48 6085523 23, e-mail: michal.pedziwiatr@uj.edu.pl 
the data on long-term results are relatively sparse and usually comprise small cohort studies [5-7].

\section{Aim}

The aim of the study was to analyse short- and long-term results of laparoscopic adrenalectomy for CS.

\section{Material and methods}

The study used a prospectively collected database, covering patients operated on for Conn's syndrome in the years $2004-2015$ at the $2^{\text {nd }}$ Department of General Surgery, Jagiellonian University Medical College. All patients underwent laparoscopic lateral transperitoneal approach adrenalectomy (LTA) and, in selected cases, single incision surgery (SILS). Inclusion criteria were: (1) age $\geq 18$ years, (2) the presence of tumour in diagnostic imaging (computed tomography or magnetic resonance imaging), (3) confirmed hormonal activity of the tumour (excessive secretion of mineralocorticosteroids). Patients were excluded from the study when: (1) full follow-up was not possible, (2) there was suspicion of malignancy in diagnostic imaging, (3) postoperative histopathology was different than adrenal adenoma or nodular adrenal hyperplasia.

Prior to surgery, all patients underwent a routine panel of laboratory tests to determine the hormonal activity of the tumour. The following parameters were measured: cortisol plasma level, free cortisol in urine, ACTH, DHEAS, 17-OH-progesterone, testosterone, plasma renin activity (PRA), aldosterone plasma level, daily secretion of methoxycatecholamines and vanillylmandelic acid (VMA) in urine. All patients underwent preoperative imaging (ultrasound, computed tomography, magnetic resonance imaging) or, if necessary, adrenal venous sampling was used to differentiate between unilateral and bilateral types of primary hyperaldosteronism (PA). Patients with clinical diagnosis of PA were referred to the Department of Endocrinology. Criteria used for PA diagnosis were described in "The Management of Primary Aldosteronism: Case Detection, Diagnosis, and Treatment: An Endocrine Society Clinical Practice Guideline" [8]. Apart from standard demographic and biochemical parameters, we additionally analysed the number of antihypertensive drugs and the duration of antihypertensive treatment prior to surgery.

Patients were operated on using the transperitoneal lateral laparoscopic access technique, simi- lar to that described in other articles [9, 10]. After surgery, all patients followed regular surgical and endocrinological follow-up (1 month, 6 months and 24 months after surgery) to determine changes in the prevalence of symptoms and normalization of laboratory parameters.

Analysed short-term outcomes included: operative time, conversion rate, intraoperative blood loss and postoperative complications. Long-term outcomes analysis included: changes in the arterial blood pressure, plasma aldosterone level, PRA, normalization of electrolytes, changes in body mass index (BMI) and the amount of received antihypertensive drugs.

In subsequent analysis, all patients were divided into 3 groups according to the level of hypertension remission 6 months after the operation. Group 1 comprised patients with complete remission (mean systolic blood pressure $<140 \mathrm{~mm} \mathrm{Hg}$ and diastolic blood pressure $<90 \mathrm{~mm} \mathrm{Hg}$ without the need for any antihypertensive drugs; normalization of sodium and potassium levels). Group 2 comprised patients with a partial response (reduction in the number or doses of antihypertensive drugs > 50\%). Group 3 comprised patients with a lack of response (persistent hypertension or reduction in the number or doses of preoperative antihypertensive drugs $<50 \%$ ).

Groups were compared in terms of demographic parameters, tumour size and histopathological results.

We also analysed the severity and duration of arterial hypertension prior to surgery, as well as the aldosteronoma resolution score (ARS) to assess the predictors for complete remission of hypertension after surgery [11].

\section{Statistical analysis}

Data were analysed using Statistica version 12.0 PL (StatSoft Inc., Tulsa, Oklahoma, USA).

Comparison of baseline data of patients was carried out using Student's $t$-test for normal distribution and the Wilcoxon rank test where the distribution was not normal. The ANOVA test was used to compare groups 1, 2 and 3. A general regression model was used to determine potential correlations.

Quantitative data are expressed as means or medians as appropriate. All procedures performed in studies involving human participants were in accordance with the ethical standards of the institutional 


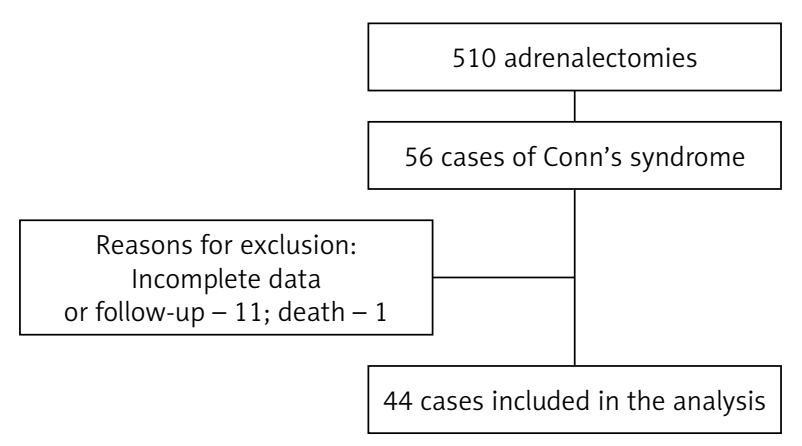

Figure 1. Patients' flow through the study

Table I. Baseline characteristics

\begin{tabular}{|lc|}
\hline Parameter & Value \\
\hline Adrenalectomy side right/left & $12 / 32$ \\
\hline Gender (F/M) & $30 / 14$ \\
\hline Age, mean \pm SD [years] & $55.2 \pm 12.5$ \\
\hline Size of the tumour - diameter, mean \pm SD [mm] & $24 \pm 17$ \\
\hline BMI before surgery, mean \pm SD [kg/m²] & $28.3 \pm 5.2$ \\
\hline $\begin{array}{l}\text { Mean duration of hypertension before surgery, } \\
\text { mean } \pm \text { SD [years] }\end{array}$ & $9.5 \pm 7.8$ \\
\hline
\end{tabular}

and national research committee and with the 1964 Helsinki declaration and its later amendments or comparable ethical standards. The study was approved by the Ethics Committee of the Jagiellonian University.

\section{Results}

Five hundred and ten laparoscopic adrenalectomies were performed in our unit in the years 2004-
2015. In 56 (10.9\%) cases patients were diagnosed with Conn's syndrome. The final analysis included 44 patients (Figure 1). Two patients were excluded from the analysis because of incomplete preoperative data. One patient died 18 months after surgery. The cause of death was not related to underlying disease or performed surgery. Nine patients were excluded from further analysis because of incomplete follow-up data. Demographic characteristics of the analysed population are presented in Table I. Preoperative diagnostic imaging confirmed the type of benign adenomas in all patients, with the mean size of $24 \mathrm{~mm}(12-90 \mathrm{~mm})$.

There were no incidents of conversion. The mean operative time was $83 \pm 31 \mathrm{~min}$. Mean intraoperative blood loss was $52 \pm 87 \mathrm{ml}$. None of the patients required postoperative blood transfusions. During the postoperative period, 3 patients had postoperative nausea or vomiting. There was 1 case of deep surgical site infection in the 30-day postoperative period and 1 case of ischemic stroke on the $14^{\text {th }}$ postoperative day.

The mean follow-up period was $76 \pm 27$ months. During the follow-up after 6 and 24 months sodium and potassium levels normalized in all patients. Similarly, the aldosterone and PRA were normal in all cases.

The average BMI before surgery was $28.3 \mathrm{~kg} / \mathrm{m}^{2}$. There were no significant changes during the follow-up 6 months after surgery $-28.0 \mathrm{~kg} / \mathrm{m}^{2}$. Full analysis of biochemical parameters before the treatment, and 6 and 24 months after treatment, is presented in Table II.

Table II. Biochemical parameters prior to surgery and 6 and 24 months after

\begin{tabular}{|lccc|}
\hline Parameter & Prior to surgery, mean \pm SD & 6 months after, mean \pm SD & $P$-value \\
\hline Aldosterone level $[\mathrm{pg} / \mathrm{ml}]$ & $661.9 \pm 420.6$ & $119.5 \pm 49.8$ & $<0.001$ \\
\hline Plasma renin activity $[\mathrm{mg} / \mathrm{ml} / \mathrm{h}]$ & $<0.2$ (median) & 0.865 (median) & $<0.05$ \\
\hline Sodium level $[\mathrm{mmol} / \mathrm{l}]$ & $143.6 \pm 2.2$ & $141.1 \pm 2.0$ & $<0.001$ \\
\hline Potassium level $[\mathrm{mmol} / \mathrm{l}]$ & $2.84 \pm 0.6$ & $4.22 \pm 0.3$ & $<0.001$ \\
\hline Parameter & Prior to surgery, mean $\pm \mathrm{SD}$ & 24 months after, mean \pm SD & $P$-value \\
\hline Aldosterone level $[\mathrm{pg} / \mathrm{ml}]$ & $661.9 \pm 420.6$ & $112.5 \pm 56.4$ & $<0.001$ \\
\hline Plasma renin activity $[\mathrm{mg} / \mathrm{ml} / \mathrm{h}]$ & $<0.2($ median) & $0.718($ median) & $<0.05$ \\
\hline Sodium level $[\mathrm{mmol} / \mathrm{l}]$ & $143.6 \pm 2.2$ & $140.2 \pm 1.9$ & $<0.001$ \\
\hline Potassium level $[\mathrm{mmol} / \mathrm{l}]$ & $2.84 \pm 0.6$ & $4.36 \pm 0.4$ & $<0.001$ \\
\hline
\end{tabular}

In the case of plasma renin activity, the distribution of features was not normal; therefore the rank test was used for statistical calculations. 
Complete remission of arterial hypertension (group 1) was achieved in 5 (11.3\%) patients, 19 (43.2\%) had a partial improvement (group 2), and in $20(45.5 \%)$ the response to the surgery was unsatisfactory (group 3).

The comparison of three groups showed statistically significant differences in age, duration of hypertension and ARS. The remaining analysed pa- rameters were not statistically significant at 6 and 24 months after surgery.

General regression model analysis showed a statistically significant correlation between the age of patients and postoperative recurrence of hypertension (Table III). Only $50 \%$ of patients with preoperative ARS 4 or 5 had complete remission of hypertension 6 months after surgery. $37.5 \%$ of them were

Table III. Results after 6 and 24 months

\begin{tabular}{|c|c|c|c|c|c|c|c|c|}
\hline \multirow[t]{2}{*}{ Parameter } & \multicolumn{4}{|c|}{ Results after 6 months in groups } & \multicolumn{4}{|c|}{ Results after 24 months in groups } \\
\hline & $\begin{array}{l}\text { Group } 1 \text { - } \\
\text { complete } \\
\text { remission }\end{array}$ & $\begin{array}{l}\text { Group } 2- \\
\text { partial } \\
\text { remission }\end{array}$ & $\begin{array}{l}\text { Group } 3- \\
\text { lack of } \\
\text { response }\end{array}$ & $P$-value & $\begin{array}{l}\text { Group } 1- \\
\text { complete } \\
\text { remission }\end{array}$ & $\begin{array}{l}\text { Group } 2- \\
\text { partial } \\
\text { remission }\end{array}$ & $\begin{array}{l}\text { Group } 3- \\
\text { lack of } \\
\text { response }\end{array}$ & $P$-value \\
\hline $\begin{array}{l}\text { Number of } \\
\text { patients (\%) }\end{array}$ & $5(11.3)$ & $19(43.2)$ & $20(45.5)$ & & $6(13.6)$ & $20(45.4)$ & $18(40.9)$ & \\
\hline $\begin{array}{l}\text { Histology type } \\
\text { (adenoma/ } \\
\text { hyperplasia) }\end{array}$ & $4 / 1$ & $14 / 5$ & $13 / 7$ & 0.74 & $5 / 1$ & $14 / 6$ & $13 / 5$ & 0.81 \\
\hline $\begin{array}{l}\text { Median ARS } \\
\text { before surgery } \\
(I Q R)\end{array}$ & $4(4-5)$ & $2(1-3)$ & $1(1-2)$ & 0.03 & $4(3-5)$ & $1(1-2)$ & $1(1-3)$ & 0.02 \\
\hline $\begin{array}{l}\text { Median duration } \\
\text { of arterial } \\
\text { hypertension } \\
(\text { IQR) [years] }\end{array}$ & $1(1-3)$ & $6(4-10)$ & $10(5-15)$ & 0.04 & $2.5(1-5)$ & $6(4-10)$ & $10(5-15)$ & 0.09 \\
\hline $\begin{array}{l}\text { Median lesion } \\
\text { size in CT (IQR) } \\
{[\mathrm{cm}]}\end{array}$ & $2(1.9-2.5)$ & $1.8(1.4-2.6)$ & $2(1.65-2.9)$ & 0.64 & $1.75(1.5-2)$ & $1.8(1.45-2.75)$ & $2.1(1.6-2.9)$ & 0.41 \\
\hline Male/female & 0.25 & 0.36 & 0.67 & 1.00 & 0.20 & 0.41 & 0.67 & 1.00 \\
\hline $\begin{array}{l}\text { Mean BMI } \\
\text { before surgery } \\
\text { (SD) }\left[\mathrm{kg} / \mathrm{m}^{2}\right]\end{array}$ & $27.92(5.87)$ & $27.96(4.75)$ & $28.43(5.47)$ & 0.89 & $25.68(6.35)$ & $29.59(5.64)$ & $27.73(3.84)$ & 0.22 \\
\hline $\begin{array}{l}\text { Median systolic } \\
\text { pressure before } \\
\text { surgery (IQR) } \\
{[\mathrm{mm} \mathrm{Hg}]}\end{array}$ & $140(130-160)$ & $140(140-150)$ & $140(140-150)$ & 0.66 & $145(140-155)$ & $145(140-150)$ & $150(140-150)$ & 0.87 \\
\hline $\begin{array}{l}\text { Median diastolic } \\
\text { pressure before } \\
\text { surgery (IQR) } \\
{[\mathrm{mm} \mathrm{Hg}]}\end{array}$ & $90(90-100)$ & $90(90-100)$ & $90(80-90)$ & 0.18 & $90(90-95)$ & $90(80-95)$ & $90(90-100)$ & 0.99 \\
\hline $\begin{array}{l}\text { Mean blood } \\
\text { pressure before } \\
\text { surgery (SD) } \\
{[\mathrm{mm} \mathrm{Hg}]}\end{array}$ & $110(8.8)$ & $110.8(5.9)$ & $106.8(6.8)$ & 0.24 & $110.8(6.3)$ & $107.8(6.8)$ & $110.0(6.8)$ & 0.55 \\
\hline $\begin{array}{l}\text { Mean age (SD) } \\
\text { [years] }\end{array}$ & $42.4(18.8)$ & $53.68(10.7)$ & $59.9(10.0)$ & 0.01 & $42.2(16.8)$ & $53.5(9.9)$ & $69.5(9.6)$ & 0.01 \\
\hline $\begin{array}{l}\text { Mean amount of } \\
\text { antihypertensive } \\
\text { drugs prior to } \\
\text { surgery (SD) }\end{array}$ & $1.0(1.2)$ & $2.7(1.2)$ & $2.5(0.9)$ & 0.01 & $1.2(1.5)$ & $2.9(1.0)$ & $2.3(0.9)$ & 0.01 \\
\hline
\end{tabular}


Table IV. Preoperative ARS and remissions after 6 months

\begin{tabular}{|lccc|}
\hline Preoperative ARS & Group 1 - complete remission & Group 2 - partial remission & Group 3 - lack of response \\
\hline $0-1$ & $4.40 \%$ & $39.10 \%$ & $56.50 \%$ \\
\hline $2-3$ & $0.00 \%$ & $53.85 \%$ & $46.15 \%$ \\
\hline $4-5$ & $50.00 \%$ & $37.50 \%$ & $12.50 \%$ \\
\hline
\end{tabular}

Table V. Changes in arterial hypertension remission 6 and 24 months after surgery

\begin{tabular}{|lccc|}
\hline \multicolumn{4}{|c|}{ Changes 24 months after surgery in comparison to 6 months after } \\
\hline & Number (\%) & Number (\%) \\
\hline Group 1 to group 2 & $1(20)$ & Group 2 to group 1 & $2(11)$ \\
\hline Group 2 to group 3 & $4(21)$ & Group 3 to group 2 & $6(30)$ \\
\hline
\end{tabular}

assigned to group 2 (Table IV). In 8 cases hypertension control improved (upgrade to groups with better hypertension control) whereas 5 other patients were downgraded to groups with worse hypertension control. In total, there were changes in $29.5 \%$ of the patients (Table V).

\section{Discussion}

Historically, primary aldosteronism, most commonly being Conn's syndrome, has been considered a rare cause of hypertension, responsible for about $1 \%$ of cases [12]. However, recent data, based on the results of population studies from Central Europe, revised this opinion. Studies have shown that increased aldosterone levels and decreased plasma renin activity are present in up to $10 \%$ of cases of hypertension and up to $20 \%$ of patients suffering from treatment-resistant hypertension $[13,14]$.

Generally, it is considered that adrenalectomy is the only treatment leading to complete recovery $[15,16]$. When compared to drug treatment, it allows for better management of hypertension, hypokalaemia and left ventricle hypertrophy $[5,17]$. Our analysis showed that adrenalectomy provided effective normalization of biochemical parameters. However, in the case of hypertension the normalization is not as satisfactory.

Postoperative complications were observed in $5(11.3 \%)$ patients in total. When analysing our results of LTA operations, we found only 1 patient suffering from a major postoperative complication (ischaemic stroke 2 weeks after surgery). The mortality rate in the postoperative period (6 months after surgery) in our material was $0 \%$. None of the patients required blood transfusions. Our observations are in agreement with results of other authors $[5,18,19]$. Therefore, we can confirm that laparoscopic adrenalectomy with transperitoneal access for CS is a safe procedure with low risk of complications and should be the gold standard for treatment of this disease $[2,8,20]$. We observed a different number of lesions localized in left and right adrenal glands. Although we cannot find an explanation for this observation, it is clinically irrelevant since usually there are no differences in perioperative outcomes between left and right adrenalectomy, which is similar to other studies [3, 20, 21].

In this study we observed normalisation of biochemical parameters (sodium, potassium, aldosterone and ARO) in all patients 6 months after surgery. Similar results were presented in other publications $[18,22,23]$. Moreover, biochemical parameters remained normal 24 months after surgery. Therefore, we can conclude that there is no need for routine long-term monitoring of these parameters postoperatively in all patients in whom normalisation was observed.

In the case of arterial hypertension, complete remission was obtained in $11.3 \%$ of patients and in a further $43.2 \%$ of patients partial remission was achieved. The results are significantly worse than the data presented by other authors where up to $30-60 \%$ of patients met the criteria of complete hypertension remission [6, 22, 24]. When comparing this relatively low rate of complete remission of hypertension with the rate of complications one can get the impression that they are similar and for this 
reason a question arises whether adrenalectomy is indeed a good treatment. However, one has to bear in mind that practically all complications were minor and short-term. This, together with very good biochemical improvements, speaks for the clear benefits of LTA. However, a careful assessment of patients might help to select patients who would not benefit from surgery in terms of hypertension, and such patients must be informed prior to surgery that it probably will not lead to clinical improvement.

Compared with other studies, we only found differences in two parameters: mean age of the cohort and duration of hypertension prior to the surgery - our patients were in general older with longer history of hypertension. We observed that both of these parameters, in addition to ARS score and the number of antihypertensive drugs, are independent risk factors for persistent hypertension after surgical treatment. In our opinion, that duration of hypertension and hyperaldosteronism prior to surgery may lead to remodelling of the left ventricle and smooth muscle tissue of arteries and can be the cause of persistent hypertension, despite the removal of the cause of hyperaldosteronism [25]. In addition, patients' age is an independent risk factor for hypertension after adrenalectomy, as has been confirmed in our and other studies [24, 26]. We assume that some patients in our cohort might have had pre-existing, undiagnosed primary hypertension, imposed with concomitant secondary hypertension associated with CS. In these cases, only a partial remission associated with the removal of the cause of secondary hypertension occurred.

Interestingly, our study did not confirm the predictive value of the ARS. Only $50 \%$ of patients with an ARS of 4 or 5 achieved total normalisation of hypertension. This is different from previous results showing hypertension remission rates of over $75 \%$ $[11,24,27]$. Although our analysis showed a significant difference between the ARS score in groups of hypertension remission after surgery, only 2 of 4 parameters included in the ARS were independent factors of normalization of arterial blood pressure in our population. Similar findings were recently published by other authors [28].

In our opinion, it seems reasonable to search for more effective tools allowing one to predict resolution of hypertension after surgery caused by CS, as proposed by Utsumi et al. [29].

Finally, we would like to highlight the variability of hypertension remission during long-term fol- low-up. Almost $30 \%$ of our patients changed their status during 24 months of follow-up (either improved or deteriorated). We did not find any statistically significant differences between these groups, but this observation suggests that all patients after surgery, even those with complete remission of hypertension, require long-term regular blood pressure control [30].

A limitation of our study is the relatively small size of the cohort, as well as the wide time span of patient enrolment in the study (almost 12 years), during which trends of hypertension treatment changed, and this may have had an impact on our results. However, we were still able to achieve an appropriate long-term observation, and the analysed cohort allowed us to perform reliable statistical measurements. Finally, since the management of hypertension changes rapidly, we are not able to select a large enough number of patients with only one type of treatment.

\section{Conclusions}

Laparoscopic adrenalectomy is a safe method of treatment for CS. Although it effectively eliminates electrolyte imbalance, it does not allow for the complete remission of hypertension in the majority of patients, especially in the elderly group. We did not find the ARS to be an effective tool in predicting postoperative resolution of hypertension.

\section{Conflict of interest}

The authors declare no conflict of interest.

\section{References}

1. Hannemann A, Wallaschofski H. Prevalence of primary aldosteronism in patient's cohorts and in population-based studies: a review of the current literature. Horm Metab Res 2012; 44: 157-62.

2. Smith CD, Weber CJ, Amerson JR. Laparoscopic adrenalectomy: new gold standard. World J Surg 1999; 23: 389-96.

3. Pędziwiatr M, Wierdak M, Ostachowski M, et al. Single center outcomes of laparoscopic transperitoneal lateral adrenalectomy - lessons learned after 500 cases: a retrospective cohort study. Int J Surg 2015; 20: 88-94.

4. Budzyński A, Pędziwiatr M, Matłok M, et al. Preliminary experience with transperitoneal single incision laparoscopic surgery adrenalectomy. Videosurgery Miniinv 2010; 5: 87-92.

5. Herd A, Harman R, Taylor E. Surgical outcomes following laparoscopic adrenalectomy for treatment of Conn's syndrome (primary hyperaldosteronism) between 1999 and 2006. N Z Med J 2010; 123: 50-6. 
6. Pang TC, Bambach C, Monaghan JC, et al. Outcomes of laparoscopic adrenalectomy for hyperaldosteronism. ANZ J Surg 2007; 77: 768-73.

7. Sywak M, Pasieka JL. Long-term follow-up and cost benefit of adrenalectomy in patients with primary hyperaldosteronism. Br J Surg 2002; 89: 1587-93.

8. Funder JW, Carey RM, Mantero F, et al. The management of primary aldosteronism: case detection, diagnosis, and treatment: an Endocrine Society Clinical Practice Guideline. J Clin Endocrinol Metab 2016; 101: 1889-916.

9. Natkaniec M, Pędziwiatr M, Wierdak M. Laparoscopic adrenalectomy for pheochromocytoma is more difficult compared to other adrenal tumors. Videosurgery Miniinv 2015; 10: 466-71.

10. Major P, Mattok M, Pędziwiatr M, et al. Do we really need routine drainage after laparoscopic adrenalectomy and splenectomy? Videosurgery Miniinv 2011; 7: 33-9.

11. Zarnegar R, Young WF Jr, Lee J, et al. The aldosteronoma resolution score: predicting complete resolution of hypertension after adrenalectomy for aldosteronoma. Ann Surg 2008; 247: 511-8.

12. Conn JW. Primary aldosteronism. J Lab Clin Med 1955; 45: 661-4.

13. Douma S, Petidis K, Doumas M, et al. Prevalence of primary hyperaldosteronism in resistant hypertension: a retrospective observational study. Lancet 2008; 371: 1921-6.

14. Strauch B, Zelinka T, Hampf M, et al. Prevalence of primary hyperaldosteronism in moderate to severe hypertension in the Central Europe region. J Hum Hypertens 2003; 17: 349-52.

15. Wu VC, Wang SM, Chang CH, et al. Long term outcome of Aldosteronism after target treatments. Sci Rep 2016; 6: 32103.

16. Reimel B, Zanocco K, Russo MJ, et al. The management of aldosterone-producing adrenal adenomas: does adrenalectomy increase costs? Surgery 2010; 148: 1178-85.

17. Catena C, Colussi G, Lapenna R, et al. Long-term cardiac effects of adrenalectomy or mineralocorticoid antagonists in patients with primary aldosteronism. Hypertension 2007; 50: 911-8.

18. Goh BK, Tan YH, Yip SK, et al. Outcome of patients undergoing laparoscopic adrenalectomy for primary hyperaldosteronism. JSLS 2004; 8: 320-5.

19. Meria P, Kempf BF, Hermieu JF, et al. Laparoscopic management of primary hyperaldosteronism: clinical experience with 212 cases. J Urol 2003; 169: 32-5.

20. Kokorak L, Soltes M, Vladovic P, Marko L. Laparoscopic left and right adrenalectomy from an anterior approach - is there any difference? Outcomes in 176 consecutive patients. Videosurgery Miniinv 2016; 11: 268-73.

21. lacobone M, Citton M, Viel G, et al. Approach to the surgical management of primary aldosteronism. Gland Surg 2015; 4: 69-81.

22. Citton M, Viel G, Rossi GP, et al. Outcome of surgical treatment of primary aldosteronism. Langenbecks Arch Surg 2015; 400: 325-31.

23. Jiang SB, Guo XD, Wang HB, et al. A retrospective study of laparoscopic unilateral adrenalectomy for primary hyperaldosteronism caused by unilateral adrenal hyperplasia. Int Urol Nephrol 2014; 46: 1283-8.

24. Aronova A, Gordon BL, Finnerty BM, et al. Aldosteronoma resolution score predicts long-term resolution of hypertension. Surgery 2014; 156: 1387-92.
25. Luther JM. Aldosterone in vascular and metabolic dysfunction. Curr Opin Nephrol Hypertens 2016; 25: 16-21.

26. Sawka AM, Young WF, Thompson GB, et al. Primary aldosteronism: factors associated with normalization of blood pressure after surgery. Ann Intern Med 2001; 135: 258-61.

27. Utsumi T, Kawamura K, Imamoto T, et al. High predictive accuracy of Aldosteronoma Resolution Score in Japanese patients with aldosterone-producing adenoma. Surgery 2012; 151: 437-43.

28. Pasquier L, Kirouani M, Fanget F, et al. Assessment of the aldosteronoma resolution score as a predictive resolution score of hypertension after adrenalectomy for aldosteronoma in French patients. Langenbecks Arch Surg 2017; 402: 309-14.

29. Utsumi T, Kamiya N, Endo T, et al. Development of a novel nomogram to predict hypertension cure after laparoscopic adrenalectomy in patients with primary aldosteronism. World J Surg 2014; 38: 2640-4.

30. Williams TA, Lenders JWM, Mulatero P, et al. Outcomes after adrenalectomy for unilateral primary aldosteronism: an international consensus on outcome measures and analysis of remission rates in an international cohort. Lancet Diabetes Endocrinol 2017; 5: 689-99.

Received: 11.01.2018, accepted: 2.03.2018. 